\section{Commentary: Pulmonary valve replacement: A good option with room for improvement}

\author{
James Quintessenza, MD
}

In this issue of the Journal, Baird and colleagues ${ }^{1}$ report on 1278 patients younger than 30 years undergoing pulmonary valve replacement. This multicenter, retrospective review is consistent with other reports in the literature. It is known that bioprostheses provide a good solution for pulmonary valve replacement. It is also known that these prostheses will degenerate with time and that this degenerative process is accelerated in younger patients. In this study, the performances of the Sorin Mitra-flow (Sorin Group USA Inc, Arvada, Colo) and the St Jude bioprosthesis (Abbott Vascular, Santa Clara, Calif) fared worse than those of the other valves used. Interestingly, the second-generation Perimount valve (Edwards Lifesciences, Irvine, Calif) seemed to do as well as the third-generation Magna valve (Edwards Lifesciences), suggesting that not much progress has been made in preventing degeneration of these valves. The overall take-home message is that we are good, but we still have a lot of work to do regarding durability.

Currently, there are multiple alternative options for patients faced with the need for lifelong for pulmonary valve replacement. In medicine, as in many other areas, this usually means that no ideal solution exists. Our interventional colleagues believe that transcatheter valves in stents seem to degenerate less. ${ }^{2}$ Perhaps some improvement will be realized with this technology; time will tell. Possibly, novel biomaterials or synthetic material such as expanded polytetrafluoroethylene ${ }^{3}$ or newer mechanical valves coupled with improved methods to

\footnotetext{
From the Department of Cardiovascular Surgery, Johns Hopkins All Children's Heart Institute, St Petersburg, Fla.

Disclosures: The author reported no conflicts of interest.

The Journal policy requires editors and reviewers to disclose conflicts of interest and to decline handling or reviewing manuscripts for which they may have a conflict of interest. The editors and reviewers of this article have no conflicts of interest.

Received for publication July 11, 2020; revisions received July 11, 2020; accepted for publication July 13, 2020; available ahead of print July 16, 2020.

Address for reprints: James Quintessenza, MD, Johns Hopkins All Children's Heart Institute, 501 6th Ave S, St Petersburg, FL 33701 (E-mail: Jquinte1@jh.edu).

J Thorac Cardiovasc Surg 2021;161:363 $0022-5223 / \$ 36.00$

Copyright (c) 2020 Published by Elsevier Inc. on behalf of The American Association for Thoracic Surgery

https://doi.org/10.1016/j.jtcvs.2020.07.042
}

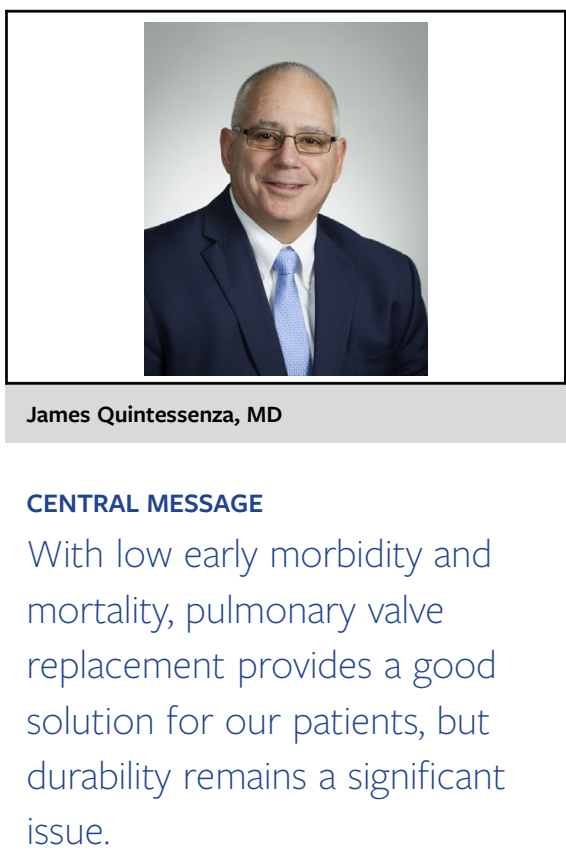

modulate the coagulation system will provide better outcomes in the future; again, we will have to wait and see. For now, patients have available what they have, and the holy grail for them is yet to come.

\section{References}

1. Baird CW, Chavez M, Sleeper LA, Borisuk MJ, Bacha EA, Burchill L, et al. Reintervention rates after bioprosthetic pulmonary valve replacement in patients younger than 30 years of age: a multicenter analysis. J Thorac Cardiovasc Surg. 2021;161:345-62.e2.

2. Georgiev S, Ewert P, Eicken A, Hager A, Hörer J, Cleuziou J, et al. Munich comparative study: prospective long-term outcome of the transcatheter Melody valve vs surgical pulmonary valve bioprosthesis with up to 12 years of follow-up. Circ Cardiovasc Interv. 2020;13:e08963.

3. Shinkawa T, Chipman C, Bozzay T, Tang X, Gossett JM, Imamura M. Outcome of right ventricle to pulmonary artery conduit for biventricular repair. Ann Thorac Surg. 2015;99:1357-66. 